\title{
Retractable Spiked Barrier Strip for Law Enforcement
}

\author{
Donna J. Marts \\ Stacey G. Barker
}

Published March 1995

Idaho National Engineering Laboratory

Lockheed Idaho Technologies Company Idaho Falls, Idaho 83415

\author{
Prepared for the \\ Department of Energy \\ Idaho Operations Office \\ Under Contract No. DE-AC07-94ID13223
}


.. $\quad \ldots$

• 


\section{DISCLAIMER}

This report was prepared as an account of work sponsored by an agency of the United States Government. Neither the United States Government nor any agency thereof, nor any of their employees, make any warranty, express or implied, or assumes any legal liability or responsibility for the accuracy, completeness, or usefulness of any information, apparatus, product, or process disclosed, or represents that its use would not infringe privately owned rights. Reference herein to any specific commercial product, process, or service by trade name, trademark, manufacturer, or otherwise does not necessarily constitute or imply its endorsement, recommendation, or favoring by the United States Government or any agency thereof. The views and opinions of authors expressed herein do not necessarily state or reflect those of the United States Government or any agency thereof. 


\section{DISCLAIMER}

Portions of this document may be illegible in electronic image products. Images are produced from the best available original document. 


\begin{abstract}
The Idaho National Engineering Laboratory has designed and laboratory tested a prototype retractable spiked barrier strip for law enforcement. The proposed system, which is ready for controlled field testing, expands the functionality of existing spiked barrier strips. A retractable barrier strip, one that can place the spikes in either the active (vertical) or passive (horizontal) position, would allow law enforcement personnel to lay the unobtrusive strip across a road far in advance of a fleeing vehicle. No damage occurs to passing vehicles until the spikes are activated, and that can be done from a safe distance and at a strategic location when the offending vehicle is close to the strip. The concept also allows the strips to be placed safely across several roadways that are potential paths of a fleeing vehicle. Since they are

not activated until needed, they are harmless to nonoffending vehicles.

The laboratory tests conducted on the system indicate that it will puncture tires only when the spikes are rotated to the active position and is safe to travel over when the spikes are in the down position. The strip itself will not cause instability to a vehicle driving over it, nor is the strip disturbed or adversely affected by vehicles driving over it. The spikes can be quickly rotated between the active (vertical) and passive (horizontal) position. However, the laboratory tests have only demonstrated that the retractable spiked barrier strip can perform its intended function in a laboratory environment. Field tests are needed to finalize the design and develop the system into a functional law enforcement tool.
\end{abstract}




\section{CONTENTS}

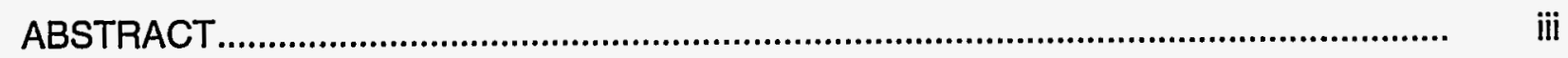

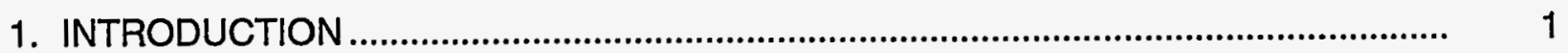

2. DESIGN REQUIREMENTS ...................................................................................

3. DESIGN METHODOLOGY AND SYSTEM DEVELOPMENT .......................................

4. INTEGRATED PROTOTYPE DESIGN....................................................................... 6

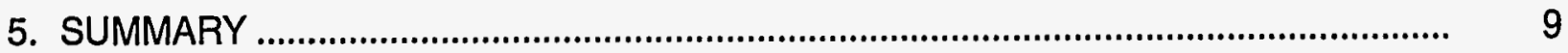




\section{INTRODUCTION}

A method commonly used by law enforcement officers to stop a vehicle fleeing at high-speed is to deploy a spiked barrier strip. The strips employ hollow spikes or needles that are picked up and imbedded in the tires of the pursued vehicle, resulting in rapid but uniform loss of air such that the vehicle comes to a controllable slow down.

Current state-of-the-art commercial spiked barrier strips require that they be placed in the path of the subject vehicle after the area is controlled or be pulled across the road just prior to the vehicle passing the selected deployment location. Both methods are reliable and result in effective puncturing of the tires of fleeing vehicles. However, it is necessary for a law enforcement officer to be in close proximity to the strips to ensure they are placed without endangering other vehicles than the one pursued. This close proximity to a vehicle chase exposes the officer to a dangerous and sometimes unpredictable situation. It is. also necessary to deploy the strips only after the path of the fleeing vehicle is determined, since the tires of any passing vehicle will be punctured.
In discussions with law enforcement agencies, it became apparent to us that few options exist to safely stop fleeing vehicles. Spiked barrier strips appear to be one of those options, but several shortcomings are recognized. In 1993, the Idaho National Engineering Laboratory (INEL) performed preliminary work on the design of a proofof-principle retractable spiked barrier strip with internal laboratory R\&D funding. In 1994 , a proposal submitted to the National Institute of Justice was selected for funding through interagency agreement. Under the agreement, the INEL was commissioned to develop a prototype retractable spiked barrier strip.

The design approach was to define the requirements, develop and fabricate a strip that met those requirements, conduct laboratory tests to evaluate the performance of the strip and refine the design, and fabricate a final prototype ready for field testing. Design consideration was given to concepts that would maintain the performance level of the commercially available strips while minimizing the fabrication costs of the final product.

\section{DESIGN REQUIREMENTS}

Design requirements for the retractable spiked barrier strip were determined from our discussions with local law enforcement personnel to get a realworld understanding of how the current strips are being used and what would make them more useful and provide additional safety for the law officer using them. The performance characteristics of the current commercial strips were also investigated and used as input to the design criteria.

The design requirements established for the system are as follows:

\section{The strip will not puncture vehicle tires until activated by the officer.}

The housing of the strip must be designed such that the spikes are completely harmless when in the retracted (horizontal) position. Vehicles must be able to pass over the strip without having their tires affected. The spikes must remain in this position, unaffected by traffic, until the law enforcement officer activates them.

The strip must be easily and quickly actuated from a distance by a single law enforcement officer.

The mechanism by which the spikes are rotated from the passive (horizontal) to the active (vertical) position and back again must be relatively fast (a couple of seconds) and easily accomplished by one officer. The officer must be able to actuate the spikes quickly to ensure that only the tires of the offending vehicle are affected by the spikes. The scenario should dictate the number of officers required, not the hardware; therefore, the strip should be designed such that one officer can actuate the strip. 
The strip must be easily deployed.

An officer must be able to rapidly deploy the strip across the roadway. The amount of time the officer is subject to a potentially dangerous situation must be minimized, and deployment must be predictable and not require special training.

The strip must be easily stored in the trunk of a patrol vehicle.

To use a spiked barrier strip, it is necessary for a patrol vehicle to get ahead of the pursuit and deploy the strip. This means the strip must be able to fit in a patrol vehicle trunk and be easily transferred from one vehicle to the next. Not only the size, but the geometry of the package must be considered, since there is other equipment routinely stored in the trunk of patrol vehicles. The strip must also be packaged such that the spikes are not a danger while the strip is being handled.

The strip must be inexpensive.

Law enforcement agencies have very limited budgets. Designing a new tool that is outside the reach of those budgets would be of little use, regardless of its effectiveness. Ideally, the retractable spiked barrier strip would be no more expensive then the current commercial strips. This would provide an improvement in usage and safety at equivalent cost of today's technology.

The strip must not cause any instability in a vehicle driving over it while the spikes are down.

The attractiveness of the retractable barrier strip is the additional safety for the law enforcement officer and its expanded use by allowing the strip to be placed on the potential paths of the fleeing vehicle. If the retractable strip in any way posed a safety concern for motorists passing over it in the retracted position, the system would be of no use. Therefore, the strip must not cause any instability in the vehicle beyond what is delivered by traveling over the cable traffic counters used today to measure traffic flow.
The actuation system must be simple, that is, inexpensive, reliable, and easy to maintain.

Law enforcement resources are a precious commodity. Money and time can always be spent elsewhere, so to design a system that requires a large amount of maintenance or training would be more hindrance than help. Radio-controlled items are flashy but typically require more maintenance, can be less reliable if not properly attended to, and usually have higher costs than mechanical systems. Heavy consideration will be given to designing the actuation system of the retractable strip such that it be reliable, easy to use, and as inexpensive as possible.

The spike housing must be unaffected by cars driving over it.

It is important that the retractable barrier strip not cause any instability for a vehicle passing over it while the spikes are down. It is equally important that the passing vehicle not displace the strip nor render it useless. The strip must withstand normal traffic load without affecting its performance.

The performance of the system must be equal to or better then the current commercial strips.

The spiked barrier strips available today are very effective at puncturing tires of fleeing vehicles. The retractable spiked barrier strip should be equally effective while providing for added safety to the law enforcement officer and expanded use by allowing it to be placed down and traveled over by nonoffensive vehicles and activated only when necessary.

The above design requirements are a foundation. We anticipate that changes will occur when the prototype unit is available for field test evaluations. User input will help define any actuator modifications needed or wanted as well as any deployment concerns. 


\section{DESIGN METHODOLOGY AND SYSTEM DEVELOPMENT}

There are numerous ways to go about designing a system such as the retractable spiked barrier strip. The methodology employed with this task was to design each component of the system, fabricate a test component part, conduct laboratory tests on that part to determine its performance, modify as necessary, and then integrate each component one at a time into the system and test the performance of the system. This step progression is effective to design a system using testing as a verification step. If testing is conducted after each addition (making only one change at a time), then it is fast and easy to identify and correct any component that is not performing adequately. This can greatly reduce the amount of time spent going down the wrong design path.

The first component designed was the housing for the retracted spike. The housing must contain the spike, allow it to be positioned horizontally and vertically, be relatively unaffected by traffic flow, and not cause instability in vehicles driving over it. A low-profile block similar to two wedges placed back to back was designed. As part of the block, a pin to hold the spikes and rotate them was also designed. A test block and pin was machined out of nylon for the initial laboratory testing. Figure 1 is a photograph of the block with a pin. The initial tests consisted of driving over the block in a passenger vehicle very slowly and observing the block. No spikes were placed in the block. The initial tests focused on the block and its stability. Speeds up to $35 \mathrm{mph}$ were achieved while driving over the block. The block did not flip up or turn over and displayed only a little sliding. The next step concerning the block was to see if it would remain stable while the spikes are vertical and puncture a tire. Tests were conducted at

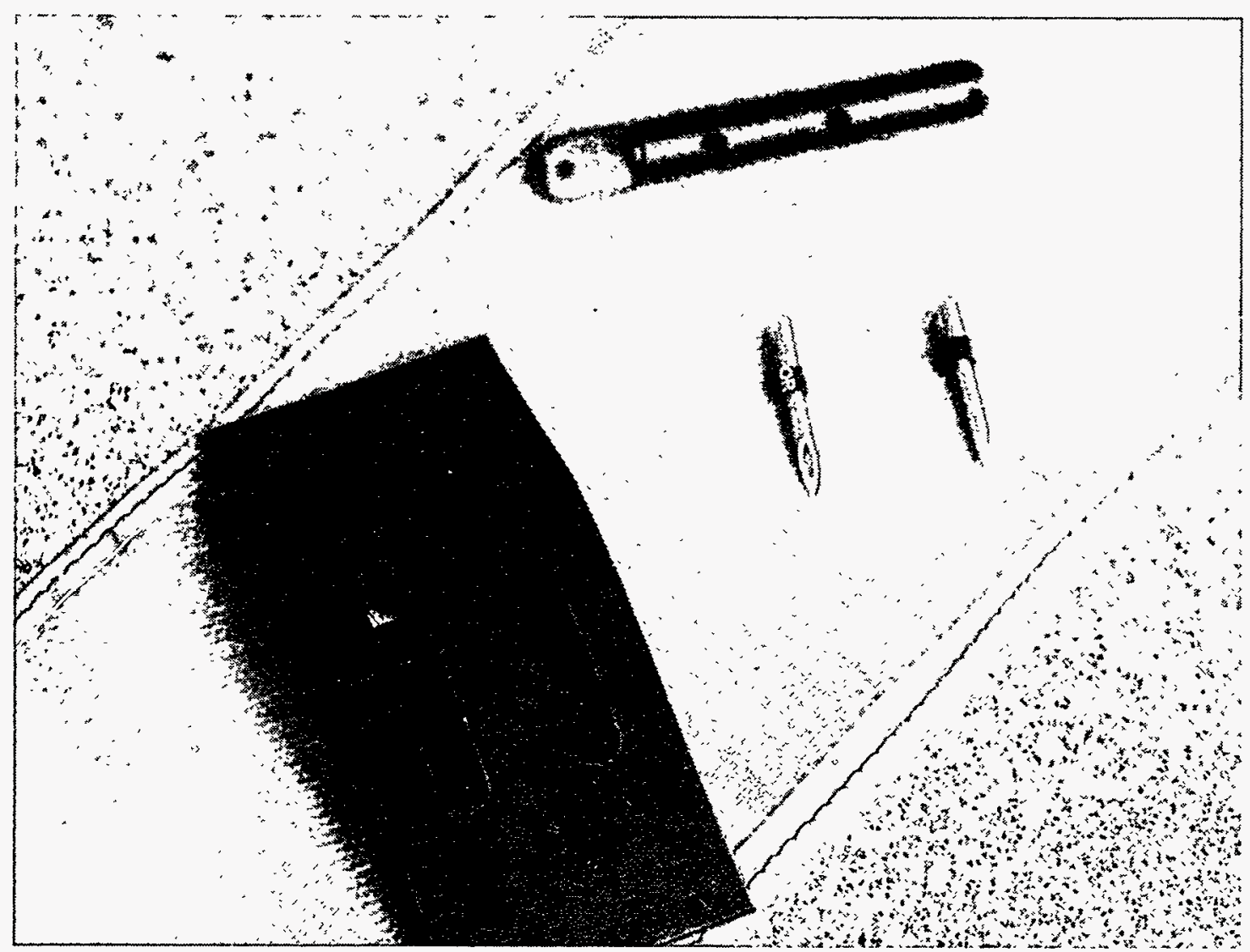

Figure 1. Test block, linking pin, and hollow spike. 
very low speeds, driving a vehicle tire over the block with spikes active. The block exhibited good stability but the performance of the spike was not as successful. The initial angle of the spike when in the active position was perpendicular to the slope of the block. This seemed reasonable since it would have the tire going over the incline meeting the spike at an angle that should be perpendicular and drive the spike into the tire. However the tests from this setup resulted in the spike bending over from the tire instead of penetrating into it. The tires did eventually flatten, but this took overnight. We used a metal plate to adjust the angle, and further tests showed that the spike would penetrate the tire without any bending when it was almost exactly vertical to the ground.

Being comfortable about the performance of the block and the spike, we next put a couple of blocks together and observed how they interacted with one another and performed as a strip. The blocks interconnect at the pins, which are slotted so that they can be connected to one another using a roll pin. This slotted joint allows the strip or blocks to be folded up when the spikes are in the down position but to be rigid when the spikes are in the up position. The blocks were put together without spikes in a strip six feet long, but the strip was somewhat unmanageable because the blocks could freely rotate around their pins independent of one another. To add stability to the strip configuration, a hole was drilled through one end of the blocks and a cable housing was inserted to string them togeth$\mathrm{er}$, as shown in Figure 2. A vehicle was then driven over the configuration at increasing speeds, from 10 to $60 \mathrm{mph}$.. The driver felt a small bump when going over the strip but there was no impact on the handling of the vehicle, and the strip remained stable; there was no overturning or flipping. The next step was to test the same configuration with the spikes in the blocks and in the vertical position. A vehicle was driven over the strip at various speeds up to $60 \mathrm{mph}$. Each time, at least the two front tires of the vehicle were punctured with two or three spikes, and the tires went flat in less than a minute. We noticed no vehicle handling difficulties and the vehicle remained on a straight line until stopped. The strip remained very stable at each test speed. As a spike was removed from the strip by the tire, the pull out force caused the strip to raise slightly,

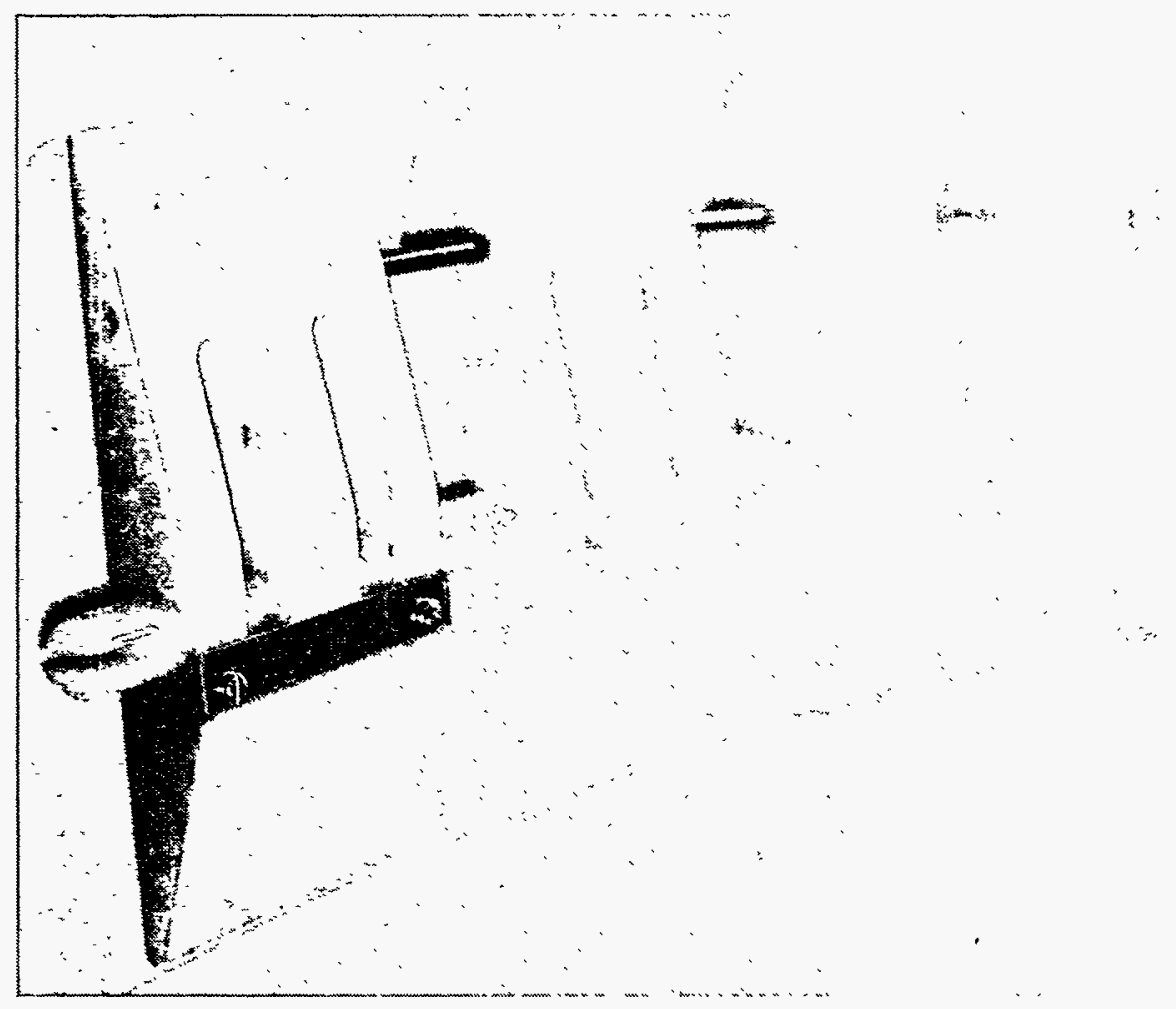

Figure 2. For stability, a cable housing was inserted though a hole drilled through the blocks. 
as shown in Figure 3, but the strip returned to rest without flipping. In a couple of the tests, pins broke at the slotted joint. Several design modifications to the joint were considered, including universal type joints, cushioned coatings, and less brittle materials. We believe the pins might be breaking owing to torsion forces on the strip while the pins are in their least flexible position with the spikes up. We noted no pin breakage during any test while the spikes were down. Instead of changing joint designs, we tested a simple method to reduce the torsion force: adding a second cable housing that strings the blocks together on the opposite end of the other cable housing. This configuration was tested at various speeds with and without puncturing tires, and no pins were broken or even cracked.

The final component to consider was the actuation mechanism. In the testing conducted to this point, the pins were manually rotated to change the spikes from the horizontal to vertical. The actuation system, thus, had simply to provide this same rotation. The first concept evaluated was to run a cable down one of the cable housings to the end of the strip, run it around a pin such that it would rotate in a pulley arrangement, and then run back down the cable housing to where it originated. This concept worked in the sense that it would rotate the pins, but the movement was a little inconsistent. The second concept evaluated was to have a bevel gear configuration rotate the pin. A cable was run down one cable housing and attached to a bevel gear. A second cable was run down the other cable housing and attached to the other side of the same bevel gear. The mating gear was connected to the last pin in the strip; thus, pulling on one cable would rotate the spikes up and pulling on the other cable would rotate the spikes down. The two cables were connected at a tee shaped handle that allowed for relatively easy operation of the pulling motion. The bevel gears were placed at both the front (closest to the operator) and back end of the strip and operated using the same handle. The operation was smoother with the bevel gears at the front end of the strip. Although the bevel gear arrangement worked, we felt that the operation was too stiff.

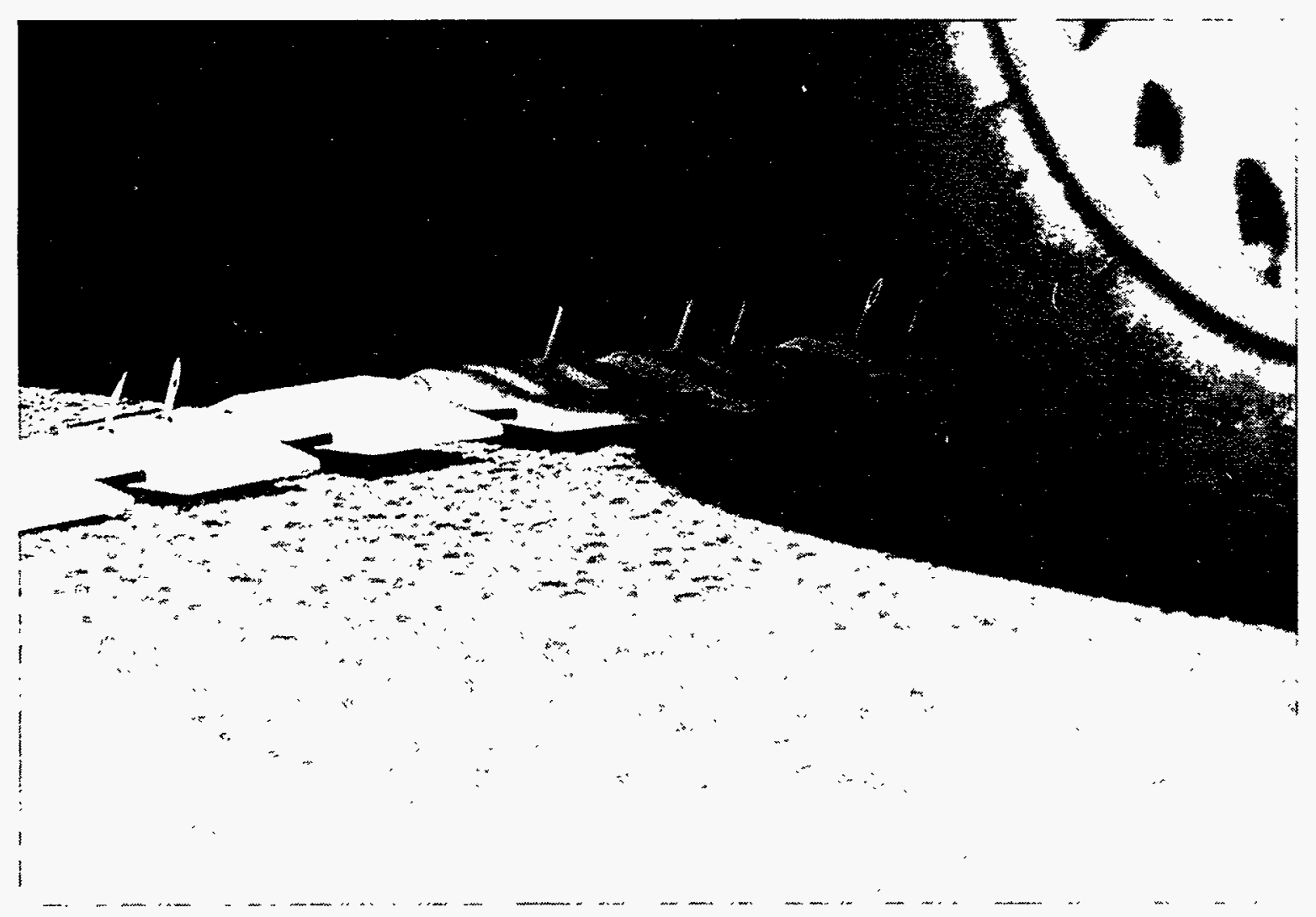

Figure 3. As the tire removed a spike from the strip, the pull out force caused the strip to raise slightly. 
We decided to modify the initial pulley concept. The pulley was placed at the front end of the strip and two cable housings were used instead of one. The tee handle was replaced with a round knob approximately three inches in diameter. This configuration provided almost effortless operation of the spikes between their two positions.

\section{INTEGRATED PROTOTYPE DESIGN}

To complete the prototype design, we integrated the components into the configuration that demonstrated the best performance as a system. Figure 4 shows this system. The pins and blocks were fabricated with only minor changes from the original component. Each block holds two spikes that are rotated from horizontal to vertical by pins that lock together to interconnect the blocks. Both the pins and blocks were fabricated from nylon. The prototype strip is approximately twelve feet long. More blocks can be interconnected to make this longer though a strip longer than fifteen feet has not been tested for smoothness of operation nor ease of use. The pin actuator is located at the front end of the strip owing to the improved performance exhibited at this location. A knob manual controller was selected because it provides quicker operation than a tee handle. The last step was to install an adjustment screw to loosen the tension in the cables to allow them to roll up. Without this tension screw, the cables could stretch or break when the strip was rolled up. Figure 5 shows the two positions of the adjustment screw.

The final step in completing the prototype was to define the packaging of the strip and how it would be deployed across a roadway. The pins are jointed such that when the spikes are in the down position, the pins can hinge and the blocks can wrap around one another, as shown in Figure 6.

The user deploys the strip from a spool while walking across a roadway. The spool, shown in Figure 7, is similar to that used to store and deploy a garden hose. The spool is approximately sixteen inches in diameter and eight inches across. The inner hub diameter is approximately six inches. This accommodates the minimum bend radius of the strip itself. A handle extends from the center of the hub past the outer diameter of the spool then crosses over and returns to the center of the hub on the other side of the spool. At the center of the hub the handle section incorporates a bearing system such that the spool can spin freely while the handle is held stationary.

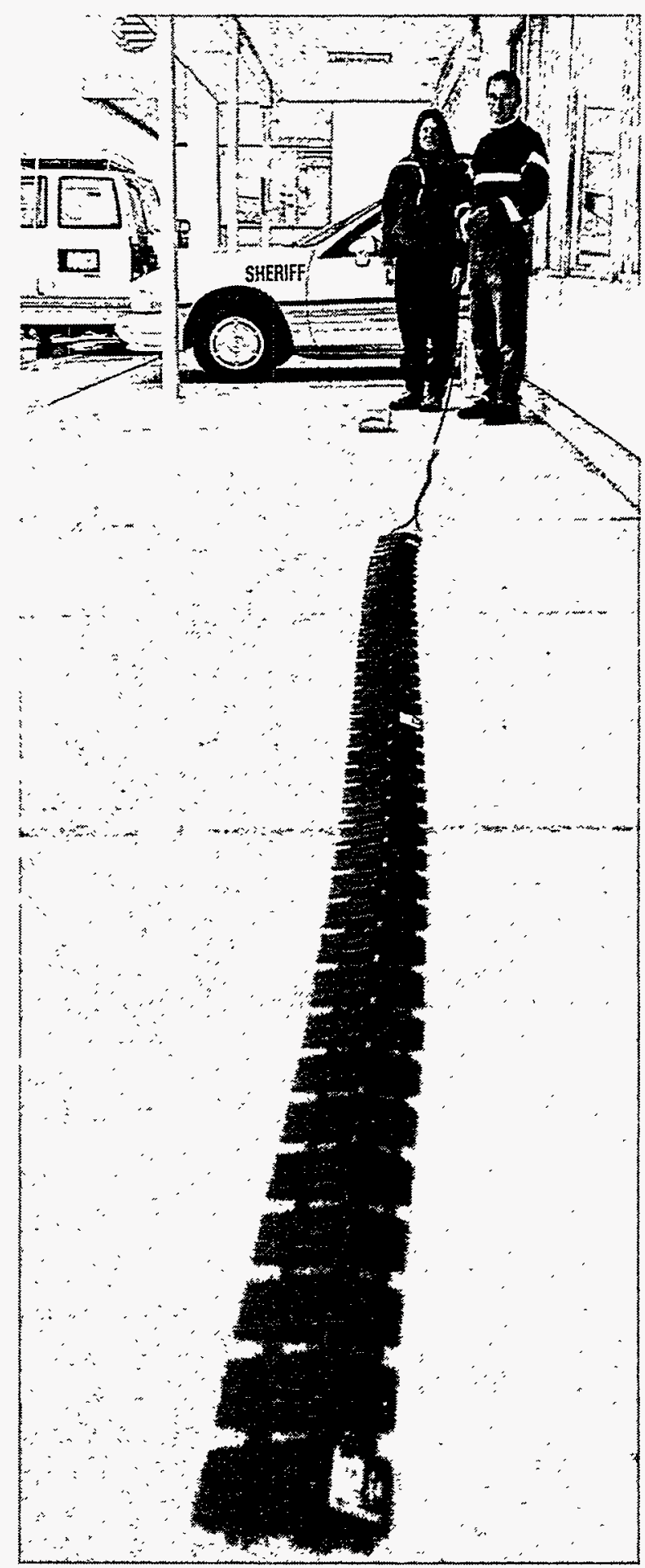

Figure 4. The system deployed. 


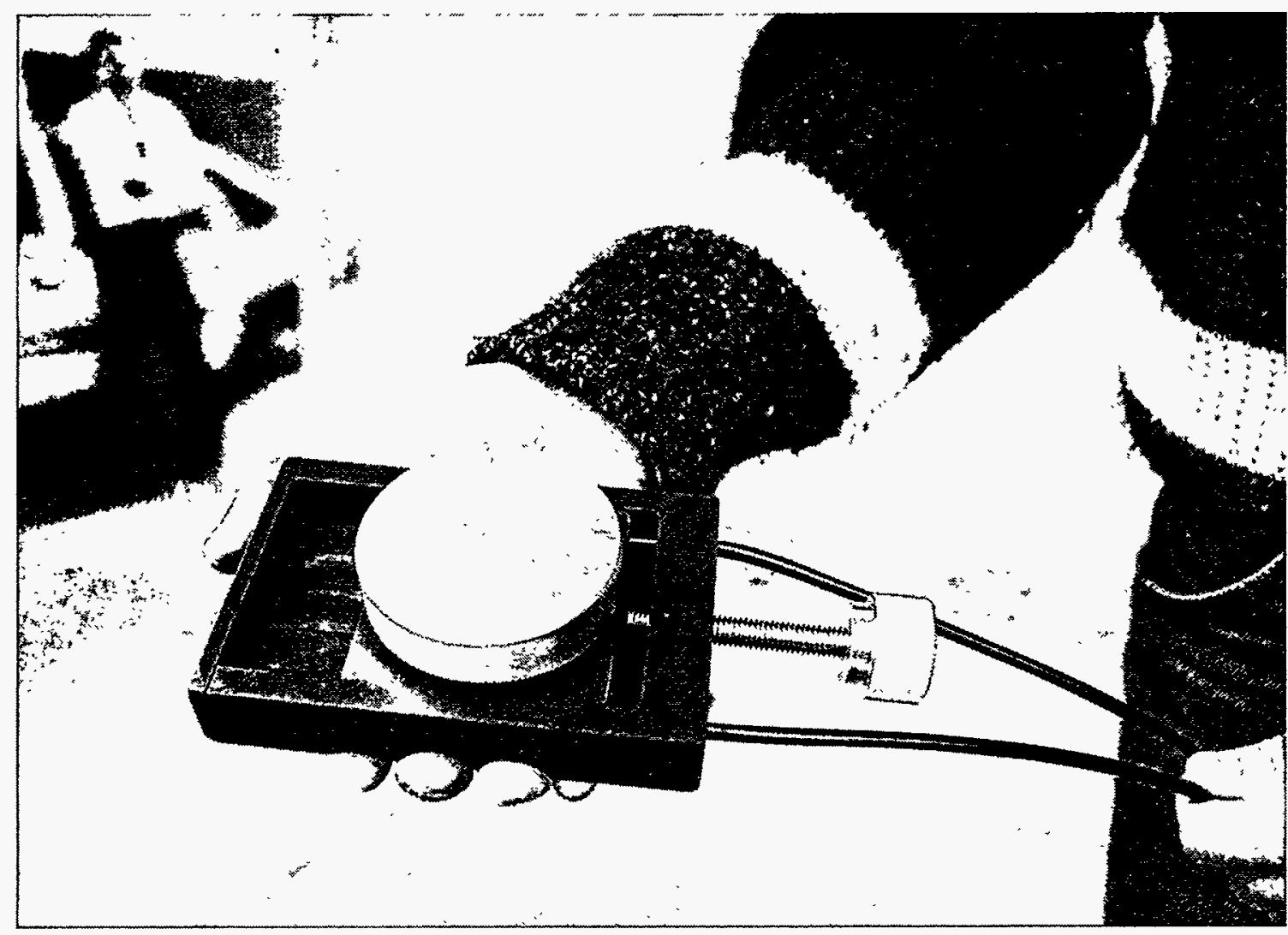

Figure 5a. The adjustment screw in the loosened position for roll up of the strip.

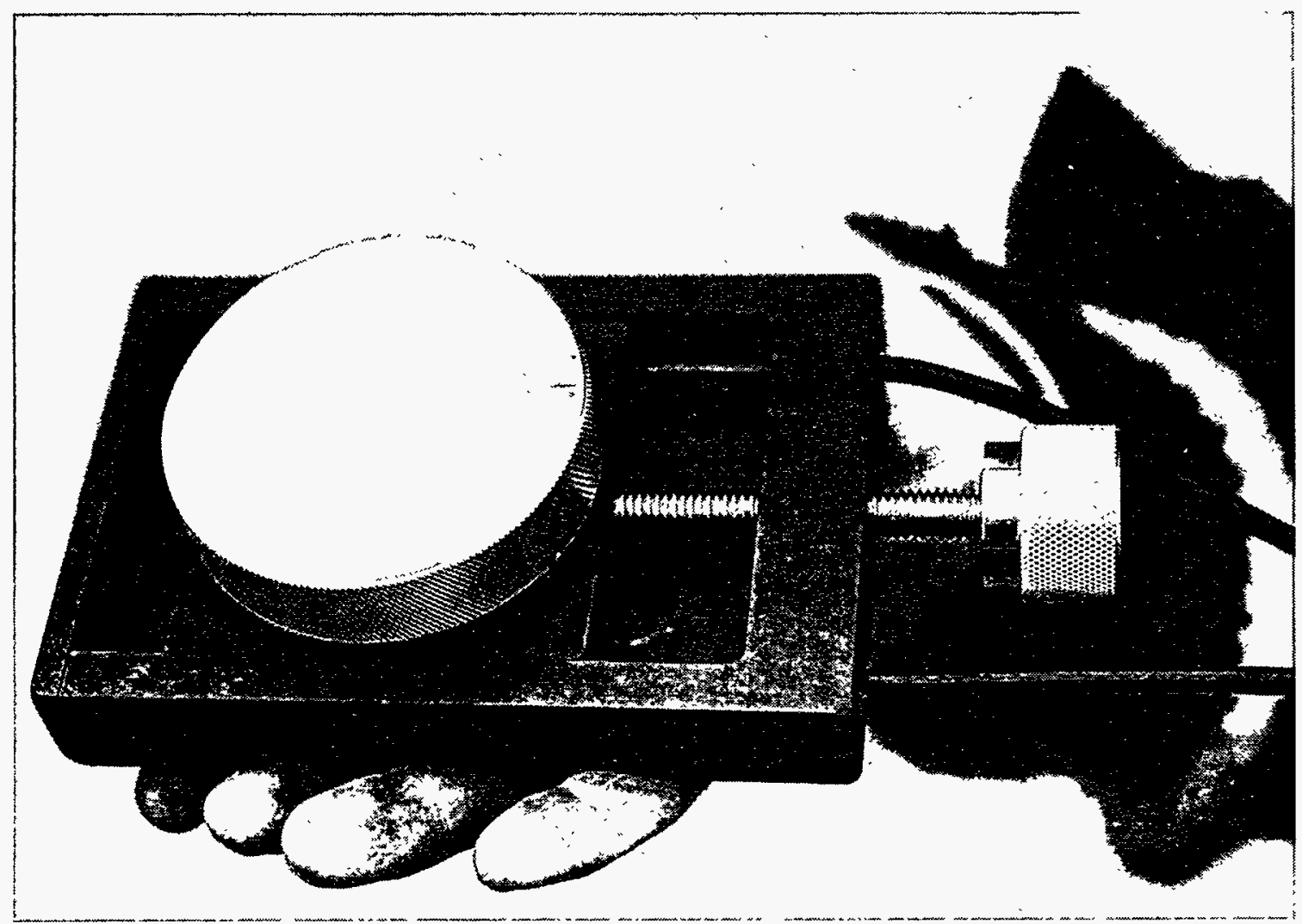

Figure 5b. The adjustment screw in the tightened position for deployment of the strip. 


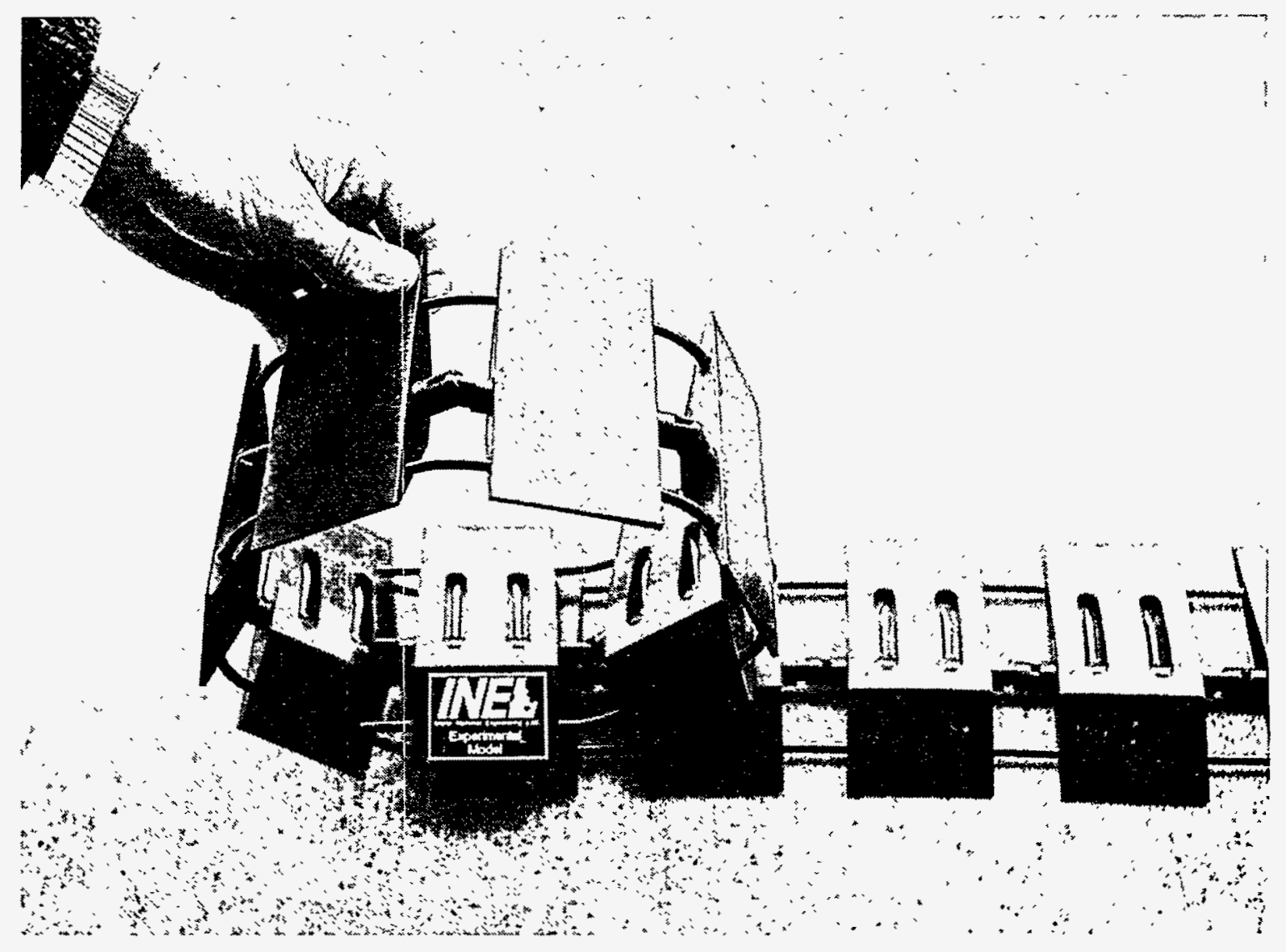

Figure 6. When the spikes are down, the blocks can wrap around one another.

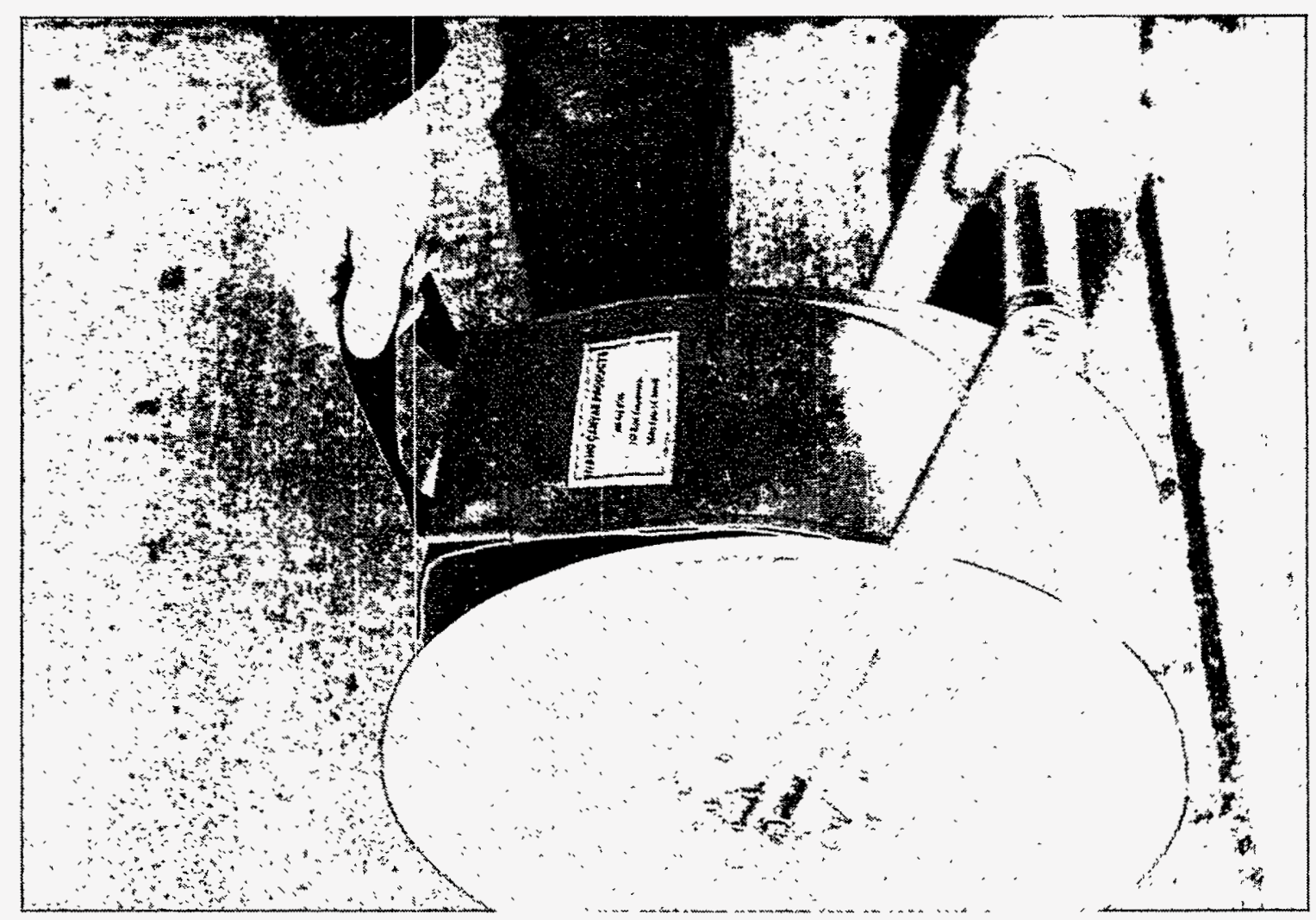

Figure 7. The spool with blocks wrapped on it. 


\section{SUMMARY}

We have produced a prototype retractable spiked barrier strip ready for controlled field testing. Our laboratory tests conducted on this system indicate that it will not puncture tires until the spikes are rotated to the active position, the strip itself will not cause any instability to a vehicle driving over it nor is the strip disturbed by vehicles driving over it, and the spikes can be quickly rotated between the active and passive position. However, the laboratory tests have only demonstrated that the retractable spiked barrier strip can perform its intended function in a laboratory environment. Field tests are needed to finalize the design and develop it into a functional law enforcement tool.

A few issues remain unresolved and should be investigated. The durability of the material is somewhat unproven. Nylon has been used on all the pieces fabricated and has given no sign of being damaged in any way. It is relatively inexpensive and can be injection molded, which is currently the manufacturing method of choice for the final product. However, the laboratory tests have been conducted tens of times not thousands of times, so verification into the long-term durability of the material should be performed. This can be accomplished simply by laying the strip across a section of road or on a track (without spikes) with a traffic counter and letting a measured number of vehicles pass over it and then by examining it for wear. If necessary, reinforcements (fiberglass strands) can be added into the nylon or a thermoplastic could be used, which would increase the materials toughness considerably.

Another item needing some type of durability testing is the pin joint. As stated above, some pins broke when the spikes were active, and only one cable housing was used to string the blocks together. The tests conducted after the second cable housing was strung between blocks resulted in no pins breaking, but, again, only a few tests were conducted. A simple test that could determine if this did correct the problem would be to conduct the same type test as for the material durability testing, only have the pins rotated in the spikes up position (without spikes in the pins). If no pins break after numerous vehicles have driven over the strip, then the design can probably be left as is. Without the pull out force of the spike into the tire this would not be a $100 \%$ assurance test, but it would be a relatively easy and inexpensive method to get a better indication on the durability of the joint. If pins do break, then a universal joint or alternate material should be developed. The strip should also be evaluated under varying road and weather conditions. The laboratory testing was performed on actual roadways, but surface roughness and road debris such as small rocks, sand, and oil were not considered. Field testing must be performed under all possible road condition scenarios and then evaluated for any necessary modifications. The final unresolved issue is the actuator control itself. We decided to leave this as a manual knob that is rotated to position the spikes up or down. The manual system is the simplest, cheapest, and provides the best feedback to the user, i.e., rotation of the knob is rotation of the spikes. The law enforcement officers are the ones that should determine if this or another method should be used. The same wires could be used but actuated by a solenoid to make this an electrical push button type operation. The system was kept as inexpensive and as simple as possible for the prototype, but nothing in the design precludes other means of actuation, such as an electrical or pneumatic controller.

We believe the prototype is ready to be field tested and evaluated by the law enforcement community. Upon completion of the field testing, modifications can be made as needed to the design and it should be ready to be transferred to private industry for commercialization. 
